\title{
The Effect of Paint on the Ignition Resistance of Plywood and Chipboard
}

\author{
J. E. J. STAGGS*, H. N. PHYLAKTOU* and R. E. McCREADIE ${ }^{+}$ \\ *Department of Fuel and Energy, University of Leeds, Leeds LS2 9JT, UK \\ ${ }^{+}$Arup Fire, Admiral House, Rose Wharf, 78 East St. Leeds LS9 8EE,UK \\ Tel. +44 (0)113 343 2495, e-mail j.e.j.staggs@leeds.ac.uk
}

\begin{abstract}
In this work the influence of paint loading on the time to ignition is investigated for chipboard and plywood. Unpainted and painted specimens, 100-mm-square, 18-mmthick, were subjected to constant incident heat fluxes of 35,50 and $65 \mathrm{kWm}^{-2}$ in a cone calorimeter. The time to ignition, mass loss rate and heat release rate are reported as functions of time and of the initial dried mass of paint on the sample (as opposed to number of coats reported in previous work by others). It was found that addition of a small amount of paint (up to $2 \mathrm{~g}$ or $200 \mathrm{~g} / \mathrm{m}^{2}$ - equivalent to 2 coats) increased the ignition time by a maximum factor of approximately two. However, addition of even more paint (up to about $4.5 \mathrm{~g}$ or $450 \mathrm{~g} / \mathrm{m}^{2}$ - equivalent to 5 coats) actually reduced the ignition time by up to a factor of approximately 7 relative to the unpainted material. A critical paint loading appears to exist (which decreases with increasing external heat flux), at which the physical mechanism controlling the ignition process changes. A mathematical model with simple kinetics was used in order to interpret the results and understand the ignition behaviour.
\end{abstract}

KEY WORDS: Ignition, coatings, building materials, blistering, wood.

\section{INTRODUCTION}

Internal wall and ceiling linings often form large areas of continuous surface, which may add significantly to the fire loading of a compartment, aid the spread of flame and advance the onset of flashover. For these reasons various national and international building material regulations seek to control the use of wall and ceiling linings on the basis of the performance of such materials in standardised tests, measuring for example the speed of surface spread of flame. However, any control that is achieved on the use of such materials in building construction is limited to their "virgin" state, whilst in practice the final finish of such materials may involve painting, varnishing, papering, veneering, etc. which may significantly alter the fire performance of the base material.

The influence of such finishes is increasingly being recognised but very limited amount of research work has been published in this area. This paper aims to make a contribution to the understanding of the influence of paint on the fire performance characteristics (ease of ignition, in particular) of chipboard and plywood.

In -recent papers, McGraw \& Mower [1], Mowrer \& McGraw [2] and Mowrer [3] discussed the effects of latex paint on the ignition and flammability of gypsum wall board. Using samples with various numbers of coats of paint in cone calorimeter tests, they concluded that it was not possible to distinguish a difference in flame spread propensity based on the number of coats. In fact, in all of their tests reported in [1], the 
paint was shown to increase the time to ignition by a maximum of around $20 \%$ with the exception of the tests at the highest cone heat flux $\left(75 \mathrm{kWm}^{-2}\right)$ and with the maximum number of coats (8) where a reduction in the time to ignition of about $36 \%$ was observed.

However, when an oil based (instead of latex based) paint was used Mower [3] was able to demonstrate that ignition resistance may be dramatically reduced by the paint. Moreover, the effect of paint on ignition resistance was shown to depend on external heat flux. Typically, Mower found that time to ignition was reduced by a significant factor at certain critical paint loadings. Specifically, wallboard coated with 2 coats or more ignited in approximately one third of the time of uncoated samples or samples with only one coat, at an external heat flux of $75 \mathrm{kWm}^{-2}$. If the external heat flux was reduced to $35 \mathrm{kWm}^{-2}$, then reduction of time to ignition by a similar factor occurred after 8 coats had been applied. In that work, Mowrer suggests that the reduction in ignition resistance was brought about by the sudden rupture of bubbles of flammable gas on the surface of the pyrolysing paint, followed by local ignition of the vapour, which presumably leads to full scale ignition over the entire surface of the sample- a process he describes as "blistering". There is some evidence of the effect in earlier studies [1] although the full significance was not realised at the time. Mowrer uses the flame spread model developed by Saito et al. [4] in order to interpret his results in terms of potential for flame spread.

In this work, the cone calorimeter is again used as the fire test instrument and the results are interpreted using an extended version of a pyrolysis model developed by Staggs in previous papers $[5,6]$.

\section{EXPERIMENTAL}

\subsection{Sample Preparation}

Substrates were $100 \mathrm{~mm}$ x 100mm x 18mm-thick plywood and chipboard. The timber was supplied from a local merchant who stated the plywood was fabricated from Scandinavian timber. An average density determined from all samples tested yielded $631 \mathrm{~kg} / \mathrm{m}^{3}$ for plywood and $704 \mathrm{~kg} / \mathrm{m}^{3}$ for chipboard. Representative samples were dried in accordance with BS476 pt.20 to determine moisture content. The results were similar for both materials with moisture content between $7-8 \%$ (wet).

One coat of a water based acrylic wood primer (Dulux Quick Drying Wood Primer) was applied prior to any topcoat and the total mass of applied paint neglected this amount which measured approximately $0.65 \mathrm{~g}$. White Dulux Trade High Gloss, a solvent based paint, was used as the topcoat. By monitoring the mass change of curing paint due to solvent evaporation the amount of solvent in the paint was determined to be approximately $35 \%$.

A paintbrush was used to apply the paint. As in Mowrer's work, [3], considerable variation in the dry mass of paint per coat was found $(0.79 \mathrm{~g} \pm 0.31 \mathrm{~g})$ and so test results are quoted with reference to dry mass of applied paint rather than number of coats. After each coat was applied and dried the samples were weighed. The paint manufacturer recommended a wet application rate of $18 \mathrm{~lm}^{-2}$ which is equivalent to $56.38 \mathrm{gm}^{-2}$ wet, and assuming $35 \%$ solvent $36.65 \mathrm{gm}^{-2}$ dry. So per $100 \mathrm{~mm}^{2}$ sample $0.37 \mathrm{~g}$ should be applied per layer. This suggests that the paint was applied at a greater rate than recommended. Monitoring the mass of painted samples over time showed that no further solvent 
evaporation occurred after approximately 16 hours. Therefore samples were allowed to dry over a period of at least 16 hours before further coats were applied. Uncoated samples were used as reference samples to take into account absorption and evaporation of atmospheric moisture from the timber between application of paint layers. Thickness of the applied coating was determined by 4 micrometer measurements evenly distributed across the surface of the sample, which also confirmed an even application of the paint.

\subsection{Cone Calorimeter Tests}

The apparatus used was a standard Cone Calorimeter manufactured in accordance to ISO 5660 (1993) and ASTM E1354 (1992) supplied by Fire Testing Technology Ltd. The tests were carried out in accordance with the test procedure of ISO 5660 except in regards to the time at which the test was terminated. All tests were carried out in the horizontal orientation at heat fluxes of 35,50 and $65 \mathrm{kWm}^{-2}$. An edge frame was used in accordance with the standard resulting in a specimen surface area of $0.0088 \mathrm{~m}^{2}$ exposed to the radiant source. The instrument was calibrated at the start of each day. The cabinet door was kept closed for the duration of the test to ensure that drafts from the surroundings did not affect results.

For each type of substrate at least nine tests were carried out at each heat flux with the mass of paint on the samples being in the range of 0-4.5 g (and with the tests distributed across this range as evenly as possible). This equated to a range of 0-5 coats excluding the undercoat. The only tests that were repeated were the virgin samples. Repeats of the painted samples were not possible because of the difficulties in reproducing the exact mass of paint on a sample. Sixty tests were carried out and reported herein. The sampling interval was set to 2 seconds. All painting, drying and testing were carried out in a conditioned laboratory at a temperature of approximately $15-20^{\circ} \mathrm{C}$ and $70 \%$ humidity.

\section{MATHEMATICAL MODEL}

The role of the mathematical model in this paper is primarily to provide a framework in which the experimental results may be interpreted. Therefore, in order to keep matters relatively uncomplicated, only an extremely simple kinetic mechanism for the degradation of the coating and substrate will be used. Furthermore, we adopt the normal 1-D assumption whereby quantities are assumed to vary only with time $t$ and distance through the thickness of the sample $y$.

It is assumed that both materials degrade in a single step to produce char and volatile products according to the kinetic scheme

$$
\frac{\partial m_{1}}{\partial t}=-k m_{1}, \frac{\partial m_{2}}{\partial t}=r k(T) m_{1}, \frac{\partial m_{3}}{\partial t}=(1-r) k(T) m_{1}
$$

Here $m_{1}$ is the mass of a small sample of the virgin (unreacted) material (coating or substrate), $m_{2}$ is the mass of char formed from the virgin material, $m_{3}$ is the mass of volatile gases formed from the virgin material, $r$ is the yield of char and $k(T)$ is a temperature-dependent rate term of the form $A \exp \left(-T_{A} / T\right)$. Note the activation temperature $T_{A}$ is sometimes written as $E_{A} / R$, where $E_{A}$ is an activation energy and $R$ is the gas constant. Of course, this is a gross oversimplification of the actual degradation 
kinetics for wood or paint, but represents a leading-order approximation which hopefully encompasses most of the important behaviour. Notice in particular that dehydration of the substrate or degradation of the final char is not included in the model. Naturally different parameter values will be chosen for the coating and substrate layers. It is convenient for the analysis to define a variable $\mu$ representing the local mass fraction of virgin material, i.e. $\mu=m_{1} /\left(m_{1}+m_{2}\right)$. In terms of $\mu$, the kinetic scheme may be reduced to the equation $\partial \mu / \partial t=k(T) \mu\{(1-r) \mu-1\}$, with initial condition $\mu(y, 0)=1$, which has solution

$$
\mu=\frac{e^{-\mathrm{K}}}{r+(1-r) e^{-\mathrm{K}}}, \text { whereK }=\int_{0}^{t} k(T(y, t)) d t .
$$

The kinetic equations may also be integrated to give the total mass of solid remaining $m=$ $m_{1}+m_{2}$ as a function of $\mu$, viz.

$$
\frac{m}{m_{0}}=\frac{r}{1-(1-r) \mu}
$$

where $m_{0}$ is the initial mass.

At this point it becomes necessary to differentiate between the coating layer and the substrate and so we use a subscript $c$ to denote a variable in the coating layer and a subscript $s$ to denote a variable in the substrate. Furthermore, the subscript 0 will be used to denote an initial value, e.g. $T(y, 0)$ will be denoted by $T_{0}$.

In the substrate, we assume that volume change during degradation is negligible and so the density varies according to $\partial \rho_{s} / \partial t=-\rho_{s}\left(1-r_{s}\right) k_{s}\left(T_{s}\right) \mu_{s}$, which may be integrated to give $\rho_{s} / \rho_{s 0}=r_{s}+\left(1-r_{s}\right) e^{-\mathrm{K}}$. Conservation of energy in the substrate leads to the equation

$$
\rho_{s} c_{s} \frac{\partial T_{s}}{\partial t}=\frac{\partial}{\partial y}\left(\lambda_{s} \frac{\partial T_{s}}{\partial y}\right)-k_{s}\left(T_{s}\right) \rho_{s} L_{s} \mu_{s},
$$

where again for simplicity we assume that the specific heat capacity $c_{s}$ is a constant, $L_{S}$ is the latent heat associated with the conversion of $1 \mathrm{~kg}$ of virgin substrate into $r_{s} \mathrm{~kg}$ of char and $\left(1-r_{s}\right) \mathrm{kg}$ of volatile gas. Lastly, $\lambda_{s}$ is the thermal conductivity of the substrate which, as usual, we assume to be a function of the porosity $\phi_{s}=1-\rho_{s} / \rho_{s 0}$ of the substrate and of the form $\lambda_{s} / \lambda_{s 0}=1-\phi_{s}$.

We assume that the coating layer is thin enough so that gradients in $T_{c}$ and $\mu_{c}$ may be neglected. Under these conditions it may be shown that the energy equation in the coating layer takes the form

$$
\frac{d T_{c}}{d t}=\frac{S\left(\dot{q}_{\text {in }}^{\prime \prime}-\dot{q}_{\text {out }}^{\prime \prime}\right)}{r_{c} c_{c} m_{c 0}}\left\{1-\left(1-r_{c}\right) \mu_{c}\right\}-k_{c}\left(T_{c}\right) \mu_{c} \frac{L_{c}}{c_{c}} .
$$


Here $m_{c 0}$ is the initial mass of coating, $S$ is the area of the exposed surface of the sample, $\dot{q}_{i n}^{\prime \prime}=\varepsilon \dot{q}_{\text {cone }}^{\prime \prime}+h\left(T_{0}-T_{c}\right)+\varepsilon \sigma\left(T_{0}^{4}-T_{c}^{4}\right)$ is the net heat flux at the exposed surface of the coating, $\varepsilon$ is the emissivity of the exposed surface, $h$ is the convective heat transfer coefficient, $\sigma$ is the Stefan-Boltzmann constant and $\dot{q}_{\text {out }}^{\prime \prime}$ is the heat flux at the interface between the coating and the substrate.

Eqn. (4) is solved with the initial condition $T_{s}(y, 0)=T_{0}$ and the boundary conditions $\lambda_{s} \partial T_{s} / \partial y=\dot{q}_{\text {out }}^{\prime \prime}$ at $y=0$ and $\partial T_{s} / \partial y=0$ at $y=l$, where $l$ is the thickness of the substrate. Eqn. (5) is solved with the initial condition $T_{c}(0)=T_{0}$. At each time step $\dot{q}_{\text {out }}^{\prime \prime}$ is chosen so that $T_{s}(0, t)=T_{c}(t)$. A standard, fully implicit finite difference method with relaxation is used to solve Eqn. (4) and the implicit Euler method is used to solve Eqn. (5). The condition $T_{s}(0, t)=T_{c}(t)$ amounts to an implicit equation for $\dot{q}_{\text {out }}^{\prime \prime}$ at each time step, which is solved using Newton-Raphson iteration.

Ignition is determined using the critical mass flux (CMF) criterion in the following way (see $[6,7]$ for details). The model equations are integrated forward in time and the total mass flux of volatiles, i.e.

$$
\dot{m}_{\text {total }}^{\prime \prime}=\left(1-r_{c}\right) \frac{m_{c 0}}{S} k_{c}\left(T_{c}\right) e^{-\mathrm{K}_{c}}+\left(1-r_{s}\right) \rho_{s 0} \int_{0}^{l} k_{s}\left(T_{s}\right) e^{-\mathrm{K}_{s}} d y,
$$

is computed (the first term on the RHS being the mass flux from the coating and the second term being the mass flux from the substrate). The time to ignition is then determined from the time at which $\dot{m}_{\text {total }}^{\prime \prime}$ first reaches the CMF. Once the critical mass flux has been reached, the flame is switched on, resulting in an additional heat flux $\dot{q}_{\text {flame }}^{\prime \prime}$ on the exposed surface, and so $\dot{q}_{i n}^{\prime \prime}$ is changed accordingly to $\dot{q}_{\text {in }}^{\prime \prime}=\dot{q}_{\text {flame }}^{\prime \prime}+\varepsilon \dot{q}_{\text {cone }}^{\prime \prime}+h\left(T_{0}-T_{c}\right)+\varepsilon \sigma\left(T_{0}^{4}-T_{c}^{4}\right)$ once ignition has occurred.

Note that this is not the only ignition criterion that we could apply. However, if we assume that there is no significant difference between the volatile species from the coating and the substrate, then approach above is valid.

\section{RESULTS}

Unless otherwise stated, model predictions were computed using the following parameter values:-

Plywood parameter values:- $l=18 \mathrm{~mm}, r_{s}=0.35, \lambda_{\mathrm{s} 0}=0.37 \mathrm{Wm}^{-1} \mathrm{~K}^{-1}, \rho_{\mathrm{s} 0}=700 \mathrm{kgm}^{-3}, c_{s}$ $=2500 \mathrm{Jkg}^{-1} \mathrm{~K}^{-1}, L_{s}=0.9 \mathrm{MJkg}^{-1}, T_{A s}=12065 \mathrm{~K}, A_{s}=1.01 \times 10^{7} \mathrm{~s}^{-1}, \varepsilon=0.9$.

Chipboard parameter values:- $l=18 \mathrm{~mm}, r_{s}=0.25, \lambda_{\mathrm{s} 0}=0.50 \mathrm{Wm}^{-1} \mathrm{~K}^{-1}, \rho_{\mathrm{s} 0}=700 \mathrm{kgm}^{-3}$, $c_{s}=2500 \mathrm{Jkg}^{-1} \mathrm{~K}^{-1}, L_{s}=0.9 \mathrm{MJkg}^{-1}, T_{A s}=11218 \mathrm{~K}, A_{s}=4.68 \times 10^{6} \mathrm{~s}^{-1}, \varepsilon=0.9$.

Paint parameter values:- $r_{c}=0.1, \rho_{\mathrm{s} 0}=900 \mathrm{kgm}^{-3}, c_{s}=2800 \mathrm{Jkg}^{-1} \mathrm{~K}^{-1}, L_{s}=1.0 \mathrm{MJkg}^{-1}, T_{A s}$ $=10403 \mathrm{~K}, A_{s}=5.30 \times 10^{7} \mathrm{~s}^{-1}, \varepsilon=0.63$. 
The convective heat transfer coefficient was take as $h=10 \mathrm{Wm}^{-2} \mathrm{~K}^{-1}$, the CMF as $2.2 \mathrm{gs}^{-}$ ${ }^{1} \mathrm{~m}^{-2}$ and $\dot{q}_{\text {flame }}^{\prime \prime}=30 \mathrm{kWm}^{-2}$. Although it is included in the model, the post ignition heat flux $\dot{q}_{\text {flame }}^{\prime \prime}$ has no effect on the time to ignition. The kinetic parameters for plywood and chipboard were chosen so as to give reasonable agreement between theoretical and experimental mass flux values for cone calorimeter tests involving the substrate only. The kinetic properties for paint were chosen such that the procedural decomposition temperature was $20 \mathrm{~K}$ less than the procedural decomposition of chipboard. Obviously it would be better to choose these parameters by other methods, e.g. from TG data, but none were available at the time of writing. In any case, the model will be used primarily for qualitative purposes rather than quantitative. The thermal properties were chosen in line with literature values [8,9], the convective heat transfer coefficient is consistent with previously quoted values for the cone calorimeter and the CMF is consistent with literature values for wood (see [10] for example). Fig. 1 shows a

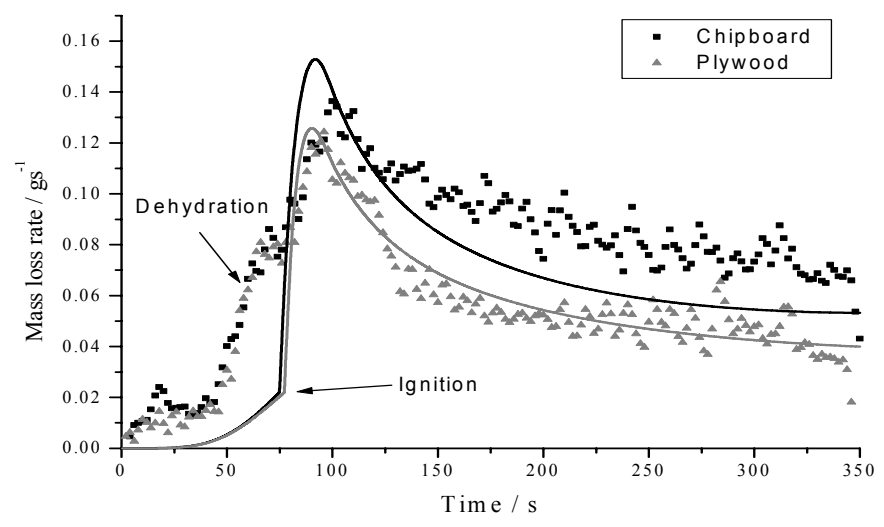

Figure 1. Comparison between predicted mass loss rate (solid curves) and experimental mass loss rate (svmbols) for unpainted substrates.

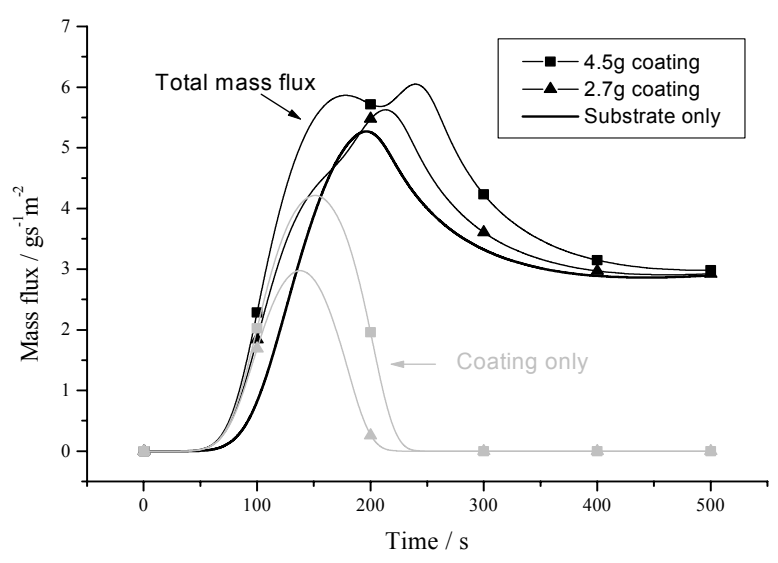

Figure 2. Example of pyrolysis model 
comparison between experimental and predicted mass loss rates for unpainted chipboard and plywood for $\dot{q}_{\text {cone }}^{\prime \prime}=35 \mathrm{kWm}^{-2}$. The initial mass loss for both samples is due to dehydration, which is not included in our model, hence the theoretical mass loss rate curves under predict the experimental curves initially.

The curves shown in Fig. 2 illustrate qualitatively the predicted effect on mass flux of adding paint to a substrate. Notice the characteristic double-peaked structure. This arises through the different degradation rates of the coating and substrate. In this case, for clarity, the emissivity of the coating is the same as the substrate and the ignition submodel is switched off. Note that as the mass of coating increases, the model predicts that a two-peaked shape will develop to the mass flux curve; most of the first peak being attributable to pyrolysis of the coating and most of the second peak being attributable to the substrate. Adding more coating has the effect of increasing the initial mass flux, increasing the peak mass flux and delaying the time at which the peak mass flux is reached. It also suggests that most of the coating will be vaporised after approximately 250 s. Naturally, if the effective heat of combustion (EHC) of the coated substrate is constant, then these trends will be reflected in the heat release rate (HRR) curves. From a practical standpoint, the HRR curve is probably a better measure than the burning rate and it has the advantage that the curves produced from the cone calorimeter are largely free of the noise associated with mass loss rate. For the samples we consider herein, EHC for practical purposes may be assumed to be constant.

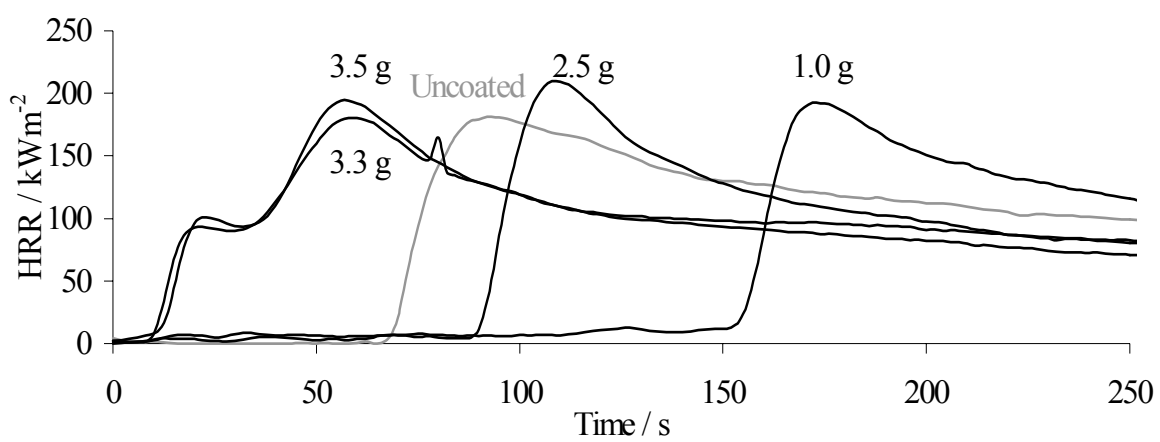

Figure 3. Effect of paint loading (expressed as dry mass of paint) on heat release rate for painted chinboard at $35 \mathrm{kWm}^{-2}$.

Fig. 3 shows experimental HRR curves for painted and unpainted chipboard samples. The tendency towards a double-peaked structure as paint loading increases is evident from the figure (although the first peak is much lower than the second). The ignition behaviour, however, is interesting. We see that addition of a small amount of paint ( $1 \mathrm{~g})$ increases the ignition time by a factor of approximately two. However addition of even more paint $(3.5 \mathrm{~g})$ actually reduces the ignition time by a factor of approximately 7 . Small amounts of paint appear to act as an ignition inhibitor, whereas larger amounts of paint act as an accelerant. 
There are many possible explanations for the inhibition effect, but the most likely seems to be that as the paint is white, addition of even a small amount changes the emissivity of the exposed surface - reducing it in this case. This does not explain the adverse effect of larger amounts of paint on ignition resistance of course. In fact if the modification of emissivity suggestion is correct, then another separate mechanism must be acting in order to produce reduced ignition resistance at higher paint loading.

In order to investigate this behaviour in more detail, model predictions for ignition times were compared to experimental values for a range of paint loadings over a range of external heat fluxes for both painted chipboard and plywood samples. The results are shown in Fig. 4. Here we plot time to ignition as a function of the dry mass of paint applied (i.e. the mass of paint after it has fully dried). The top graph corresponds to painted chipboard and the bottom graph to painted plywood. The sample size was 100 $\mathrm{mm} \times 100 \mathrm{~mm} \times 18 \mathrm{~mm}$, implying that the dry application rate in $\mathrm{gm}^{-2}$ may be found by multiplying the dry mass of coating by 100 .

The top graph of Fig. 4 illustrates the effect of the paint on the emissivity of the exposed surface. The dashed curves correspond to model predictions where the emissivity of the paint is the same as the substrate and the solid curves correspond to the case where the emissivity of the paint is $30 \%$ lower than the substrate. The symbols represent experimental values. Note that in all cases with unaltered emissivity, the model predicts a monotonic decrease in ignition time with paint loading - behaviour which is clearly not observed. If the kinetic parameters for the paint had been chosen such that the procedural decomposition temperature was higher than wood, then the model would predict a monotonic increase in ignition time with paint loading. For the case of modified emissivity, the model compares reasonably well with experimental values, reproducing the qualitative behaviour, except at higher paint loading. There appears to be a critical paint loading, which decreases with external heat flux, at which there is a large decrease from the expected time to ignition. The critical loading at $35 \mathrm{kWm}^{-2}$ appears to be between $2.5-3 \mathrm{~g}$, at $50 \mathrm{kWm}^{-2}$ it appears to be between $2-2.5 \mathrm{~g}$ and at $65 \mathrm{kWm}^{-2}$ the critical loading appears to be around $1 \mathrm{~g}$. These general trends appear again in the lower graph (plywood substrate) for the $50 \mathrm{kWm}^{-2}$ and $65 \mathrm{kWm}^{-2}$ cases, but there is no evidence of a greater than expected decrease in ignition time for the $35 \mathrm{kWm}^{-2}$ case.

At low paint loading, the model predicts that most of the volatile products at the point of ignition derive from the substrate. As paint loading increases, a greater proportion of the volatile products derives from the paint itself. Table 1 gives values calculated from the model for chipboard using an external heat flux of $35 \mathrm{kWm}^{-2}$. Hence after an initial increase in ignition time because of a reduction in the emissivity of the exposed surface, the model suggests that ignition time will decrease as paint loading increases, due to the earlier production of increased amounts of volatiles from the paint itself. In other words, as paint loading increases, ignition becomes determined by the decomposition kinetics of the paint. 


\begin{tabular}{|c|c|c|c|c|}
\hline $\begin{array}{c}\text { Dry mass of } \\
\text { paint / } \\
\mathbf{g}\end{array}$ & $\begin{array}{c}\text { Time to } \\
\text { ignition / } \\
\mathbf{s}\end{array}$ & $\begin{array}{c}\text { Mass flux } \\
\text { From } \\
\text { Paint / } \\
\mathbf{g s}^{-1} \mathbf{m}^{-2}\end{array}$ & $\begin{array}{c}\text { Mass flux } \\
\text { from } \\
\text { substrate / } \\
\mathbf{g s}^{-1} \mathbf{m}^{-\mathbf{2}}\end{array}$ & $\begin{array}{c}\text { Proportion } \\
\text { of mass flux } \\
\text { from paint } \\
\text { paint }\end{array}$ \\
\hline 0 & 74.86 & 0 & 2.2 & 0 \\
\hline 0.25 & 156.19 & 0.13 & 2.07 & 5.81 \\
\hline 0.75 & 151.40 & 0.54 & 1.66 & 24.34 \\
\hline 1.5 & 126.16 & 1.45 & 0.75 & 65.77 \\
\hline 2.5 & 108.74 & 1.84 & 0.36 & 83.65 \\
\hline 3.5 & 101.82 & 1.97 & 0.23 & 89.44 \\
\hline
\end{tabular}

Table 1. Theoretical ignition times and mass fluxes at ignition for painted chipboard at 35 $\mathrm{kWm}^{-2}$.
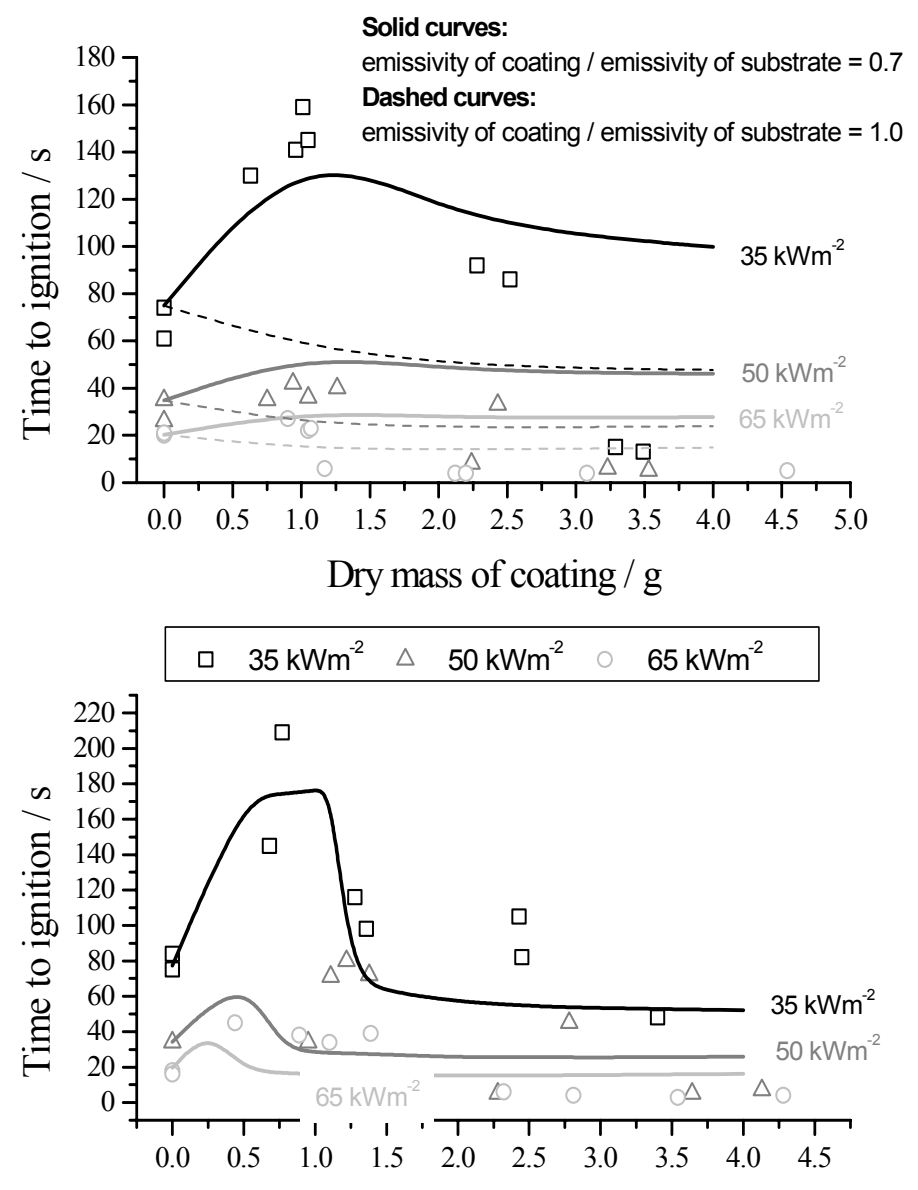

Dry mass of coating / $\mathrm{g}$

Figure 4. Comparison been predicted (curves) and experimental (svmbols) ignition times for chipboard (top) and plvwood (bottom). 
We see from Fig. 4 that this explanation does not account for the experimentally observed ignition behaviour. There is a greater reduction in time to ignition than would have occurred if decomposition kinetics was the only factor. This observation is wholly in accord with the earlier work of Mowrer [3], where reduced ignition resistance was attributed to blistering of the painted surface. Moreover, it is likely that the emissivity of the surface will change during the experiment - possibly increasing as charring occurs. This effect is not included in the model and is likely to influence results - particularly when ignition times are high. Figure 5 shows a selection of photographs taken during a cone calorimeter test on varnished plywood, intended to illustrate the blistering phenomenon (unfortunately the camera was not available during testing of the painted samples). The plywood was coated with a sufficient quantity of coloured varnish to generate significant bubbling on the surface at an external heat flux of $50 \mathrm{kWm}^{-2}$. A digital camera was used to record the ignition event, taking one frame every $0.04 \mathrm{~s}$. The top photograph clearly shows a great deal of surface activity, with bubble sizes of the order of $1 \mathrm{~cm}$ just before ignition. Ignition occurred at some time between $11.76 \mathrm{~s}$ and $11.80 \mathrm{~s}$, resulting in a rapid transition to flaming combustion across the entire surface of the sample.

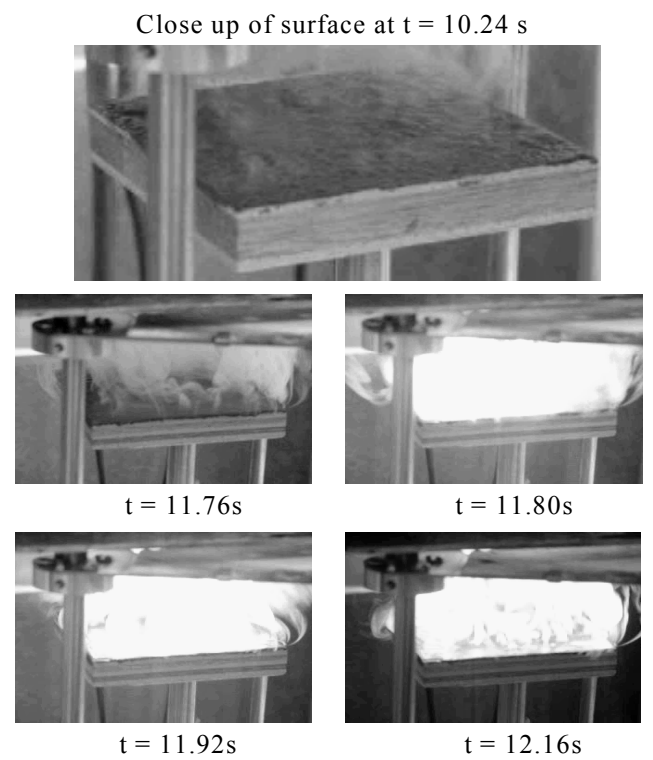

Figure 5. Ignition of varnished plywood at 50 $\mathrm{kWm}^{-2}$ in the cone calorimeter

\section{CONCLUSION}

The ignition of painted plywood and chipboard has been investigated using a cone calorimeter, over a range of incident heat fluxes. It was found that addition of a small amount of paint (up to $2 \mathrm{~g}$ or $200 \mathrm{~g} / \mathrm{m}^{2}$ - equivalent to 2 coats) increased the ignition time by a maximum factor of approximately two. However addition of even more paint (up to about $4 \mathrm{~g}$ or $400 \mathrm{~g} / \mathrm{m}^{2}$ - equivalent to 6 coats) actually reduced the ignition time by up to a factor of approximately 7. In general, a small amount of paint acted as an ignition 
inhibitor, whereas a larger amount acted as an ignition accelerant. There appears to be a critical paint loading, which decreases with increasing external heat flux, at which there is a large decrease in the time to ignition.

In order to aid our understanding of the underlying physical mechanisms for this behaviour, a mathematical model was developed based on simple kinetic mechanism for the degradation of a thin coating and a thick substrate. Ignition, resulting in an additional heat flux from the flame was switched on when the total mass of volatiles from the two layers reached a critical mass flux. In the absence of other data, some of the model parameters were calibrated to give a reasonable prediction of the virgin wood ignition behaviour, whilst others were taken from accepted literature values.

The experimental HRR curves for painted samples showed a tendency towards a doublepeaked structure as the paint loading was increased and this behaviour was predicted by the model which helped attribute the first peak to pyrolysis of the coating and most of the second peak being attributable to the substrate.

The model showed that a reduction in the emissivity of the exposed surface (because of the addition of a thin layer of white paint), would increase the ignition time and additionally suggested that the ignition time would decrease with increasing paint loading, due to ignition being effectively determined by the decomposition kinetics of the paint. However, at high paint loading, the predicted reduction in ignition time was much less than that observed experimentally, suggesting that paint decomposition kinetics was only a contributing factor and that another mechanism - not included in the model - was involved. In accord with the findings of other recent works, paint blistering and bubbling were observed in the present experiments with high paint loading and this is thought to be a possible additional mechanism for the large ignition time reduction. Incorporation of this effect is being considered as part of an on-going research programme.

The overall important finding from this work is that for wood-based wall and ceiling lining materials with sufficiently high loading of paint (such as might result over a moderate number of painting applications) the ignition resistance of the material might be significantly reduced, and this would contribute to a much faster spread of flame in a fire scenario.

\section{ACKNOWLEDGEMENTS}

The authors would like to acknowledge the help of final year UG students Mr. Alistair Morrison and Mr. Gareth Pursell-Clarke and M. Sc. Student Mr M. Perrin in conducting the cone calorimeter experiments.

\section{REFERENCES}

[1] Mowrer F. W. \& McGraw J. R. Flammability and dehydration of painted gypsum wallboard subjected to fire heat fluxes. Interflam '99 - Proceedings of the eighth international conference, 2 pp1325-1330 (1999).

[2] McGraw J. R. \& Mowrer F. W. Flammability and dehydration of painted gypsum wallboard subjected to fire heat fluxes. Fire Safety Science-Proceedings of the Sixth International Symposium pp.1003-1014 (2000). 
[3] Mowrer F. W. The effect of "blistering" on the ignition and flammability of painted gypsum wallboard. Proceedings of the Fire and Materials 2001 conference, San Francisco, USA 22-24 January, Interscience, pp197-208 (2001).

[4] Saito K., Quintiere J. G. \& Williams F. A. Upward turbulent flame spread. Fire Safety Science - Proceedings of the First International Symposium pp75-86 (1986).

[5] Staggs J. E. J. Simple mathematical models of char-forming polymers. Polymer International 49 pp1147-1152 (2000).

[6] Watt S. D., Staggs J. E. J., McIntosh A. C. \& Brindley J. A theoretical explanation of the influence of char formation on the ignition of polymers. Fire Safety Journal 36 pp421-436 (2001).

[7] Staggs J. E. J. \& Nelson M. I. A critical mass flux model for the flammability of thermoplastics. Combustion Theory and Modelling 5 pp399-427 (2001).

[8] Drysdale D. D. An introduction to fire dynamics. John Wiley \& Sons (1992).

[9] Incropera F. P. \& DeWitt D. P. Introduction to heat transfer. John Wiley \& Sons (1996).

[10] Thomson H. E. \& Drysdale D. D. Flammability of plastics II. Critical mass flux at the firepoint. Fire Safety Journal 14 pp179-88. 